\section{James B.D. Palmer, FRCP, FRCPE, FFPM}

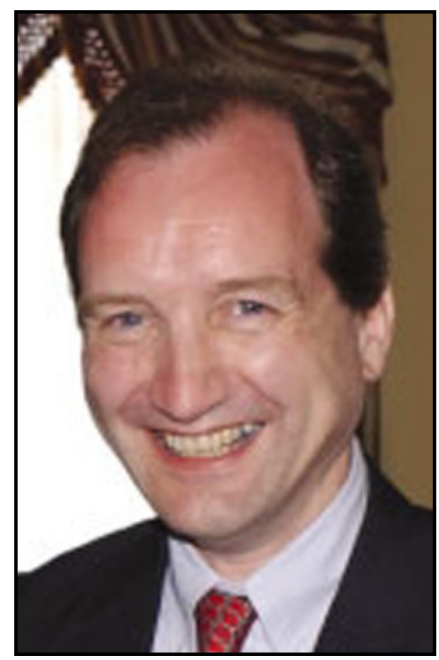

The premature death of James Palmer, aged 51, on 26 October is a tremendous loss to his family and everyone who knew him. He was firstly a consummate physician, who then had a distinguished career in pharmaceutical research and development, and became an exemplary business leader.

James was born in London, but was educated in Scotland and he graduated in medicine from Aberdeen University in 1978 with commendation and was awarded distinctions and prizes in clinical medicine and surgery. After house jobs, he became a rotating senior house officer in Aberdeen and, within 3 years of graduation, obtained his MRCP (UK). His father was a consultant chest physician in Aberdeen and after a registrar post in pulmonary medicine he obtained in November 1983 a MRC Research Fellowship working with Peter Barnes at the Royal Postgraduate Medical School in London. His main work was on neuropeptides in the lung and, over the next 5 years or so, he was co-author with leading experts of many papers on pulmonary disease and its management.

In 1985, he joined Glaxo Group Research in London and in the next 2 years was rapidly promoted, becoming Director of Respiratory Clinical Research. The development of salmeterol (Serevent) and fluticasone proprionate (Flixotide and Flixonase) was his responsibility. In this role, he demonstrated his thorough knowledge of pulmonary disease, of the underlying pathophysiology and of the clinical evaluation of new medicines in the field. In addition, the diskhaler device and controlled release salbutamol (Volmax) were developed, and he directed other re- search programmes, for instance looking at thromboxane anatagoists for asthma. Needless to say, he managed a major programme of successful regulatory submissions.

In this remarkable 5-year period, James demonstrated his personal knowledge and moreover his leadership skills. He was popular, was easily approached by everyone, and he exuded a clear philosophy of dedicated clinical research and integrity. Senior Glaxo management saw in him these invaluable qualities. With the importance of the US market, he was then transferred to Glaxo Inc. in 1990, as Vice-President Clinical Research in the Glaxo Research Institute, and there he supervised the submission and approval of three major New Drug Applications (NDAs) for Serevent, Imitrex and Flonase and four other NDAs. He created a clinical pharmacology department there, doubled the staff and set up management/leadership programmes. These efforts were rewarded in the next 2 years by promotions in Glaxo Inc., becoming Senior Vice President, Medical Operations and Chief Medical Officer. He and his family enjoyed the US, and his future career remained there as Glaxo merged with Burroughs Wellcome, who also had their US headquarters in Research Triangle Park.

Under Richard Sykes and working closely with Jim Niedel, Research Director at Glaxo Inc., he integrated the global medical operations for Glaxo Wellcome. In 1996, he was appointed Senior Vice President and Director, Group Medical and Regulatory Operations. With about 3000 staff under him, he initiated the global redesign of clinical development after the merger. Two years later, Product Strategy was added to his portfolio and he assimilated the three themes. That year he also established a policy of full disclosure of clinical trial protocols and results through the Cochrane Collaboration, making Glaxo Wellcome the first large pharmaceutical company to do so. The creation of GlaxoSmithKline (GSK) in 2000 was a second wave of integration in just over 5 years. He retained the Medical, Regulatory and Product Strategy as Senior Vice-President for New Product Development with over 5000 staff worldwide.

However, he left GSK and in December 2002 was appointed Chief Scientific Officer and President in the Pharmaceutical Research Institute of Bristol-Myers-Squibb with responsibility for all R\&D activities. Based in Princeton, New Jersey, James made a huge contribution in his short time there, leading efforts to secure the approval of three important new products: atezanavar (Reyataz), aripiprazole (Abilify) and cetaximab (Erbitux) and the regulatory filings of three more compounds. As always, his experience and expertise coupled with his sheer humanity had a powerful impact on his colleagues. He was widely admired, made many friends and is missed by all.

James always pursued excellence and had the welfare of pa- 
tients at heart - "they've a right to nothing than the best". He would always make time to talk personally to patients and patients' groups on the 'phone or face to face. Dealing with the criticisms that the pharmaceutical industry sometimes puts profit before patient interests, the role of a senior medical officer in a pharmaceutical company is to be the final professional arbiter between these potentially conflicting interests. James fulfilled this role admirably. Equally, he was prepared to present and stand by his views at the highest level of the company. He was surefooted in his decision making; never rushed, quietly assessing facts before reaching a decision or recommendation. A man of great integrity and principle, a strong leader, James' sort is critical for the effective operation of what is, at heart, an ethical and responsible industry.

Sadly, he developed a pulmonary mesothelioma, undoubtedly related to the whole-body irradiation given for a Hodgkin's lymphoma as a young man, from which he died. Throughout he continued working, not evidencing the seriousness of his condition, and his fortitude was remarkable. James had the love and support of his devoted wife, Susie, and their children, Ralph, Sarah and Alexandra. Our thoughts go to them and to his mother and two sisters, Tessa Jowell and Eske Palmer. 